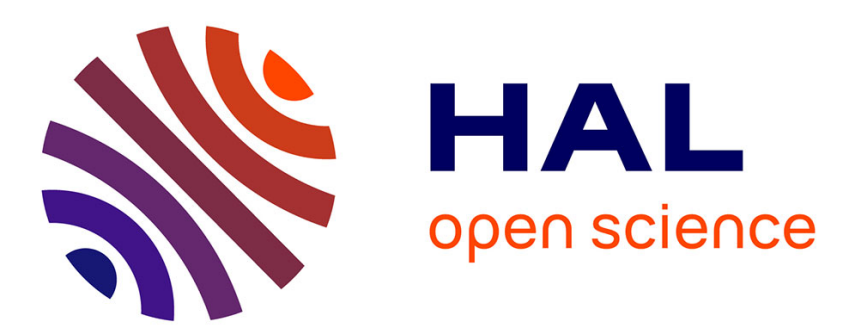

\title{
Recent advances in electrically pumped VECSELs for modelocking
}

\author{
Yohan Barbarin
}

\section{To cite this version:}

Yohan Barbarin. Recent advances in electrically pumped VECSELs for modelocking. SPIE LASE, Jan 2011, San Francisco, United States. pp.79190H, 10.1117/12.873529 hal-02549227

\section{HAL Id: hal-02549227 \\ https://hal.science/hal-02549227}

Submitted on 21 Apr 2020

HAL is a multi-disciplinary open access archive for the deposit and dissemination of scientific research documents, whether they are published or not. The documents may come from teaching and research institutions in France or abroad, or from public or private research centers.
L'archive ouverte pluridisciplinaire HAL, est destinée au dépôt et à la diffusion de documents scientifiques de niveau recherche, publiés ou non, émanant des établissements d'enseignement et de recherche français ou étrangers, des laboratoires publics ou privés. 


\title{
Recent advances in electrically pumped VECSELs for modelocking
}

\author{
Y. Barbarin \\ Department of Physics, Ultrafast Laser Physics Lab, ETH Zurich, Switzerland
}

\begin{abstract}
Vertical external cavity surface emitting lasers (VECSELs) are excellent high power semiconductor lasers with diffraction-limited circular output beam and outstanding modelocking performance even at tens of $\mathrm{GHz}$ repetition rate. The output power can be scaled up by simply increasing the mode area on the gain region. It makes them very attractive for numerous applications such as RGB displays, biomedical imaging or optical clocking of multi-core processors. Passively modelocked optically-pumped VECSELs, using a semiconductor saturable absorber mirror (SESAM), have generated shorter pulses and higher average powers than any other modelocked semiconductor laser (135-fs pulses at 35$\mathrm{mW}$ average power and 2.1-W in 4.7-ps pulses).

Electrical pumping (EP) of modelocked VECSELs is the obvious next step towards compact high-power ultrafast laser sources. In 2003, Novalux Corporation reported a continuous wave (cw) output power of nearly one Watt from their proprietary EP-VECSEL (NECSEL). The modelocking of a NECSEL has been demonstrated with $40 \mathrm{~mW}$ of average power in 57-ps pulses. Since then, very few EP-VECSEL results have been reported. Recently, we started to develop EPVECSELs designed for modelocking, which require an optimized balance between electrical resistance, optical losses, dispersion and beam quality. We discuss our design approach and present initial EP-VECSEL devices generating $>100-\mathrm{mW}$ cw power. Homogeneous current injection is achieved even for large devices, showing very good agreement with our numerical simulations. Sufficient power in a diffraction-limited beam and a carefully designed SESAM are required to modelock an EP-VECSEL.
\end{abstract}

Keywords: Semiconductor lasers, surface emitting lasers, mode-locked lasers, ultrafast lasers.

\section{INTRODUCTION}

Semiconductor lasers revolutionized the optical telecommunications with direct intensity modulation [1], today modelocked semiconductor lasers have the potential to replace bulky and expensive modelocked diode pumped solidstate lasers in many applications such as RGB displays, biomedical imaging or optical clocking of multi-core processors. Up to now, modelocked edge-emitting lasers (EEL) generate average output powers of up to $250 \mathrm{~mW}$ in picosecond pulses [2]. In EELs, the mono-mode waveguide limits the lateral scaling and the long light interaction in the waveguide introduces significant nonlinearities and noise. It is very challenging to increase the output power of modelocked EELs to the Watt regime. It can be realized by adding a tapered amplifier and an external pulse compressor like in [3], but the laser system becomes bulky and makes the use of semiconductor diodes less attractive.

Vertical external cavity surface emitting lasers (VECSELs) [4] offer excellent beam quality and high output power in the multi-Watt level and directly from the resonator. The output power can be scaled up by simply increasing the mode area on the gain region. The simple VECSEL external cavity geometry enables passive modelocking of these devices [5] using a semiconductor saturable absorber mirror (SESAM [6,7]). The use of semiconductor materials in SESAMmodelocked VECSELs allow for cheap mass production. The SESAM can even be integrated directly in the VECSEL structure. This new type of laser is called a modelocked integrated external-cavity surface emitting laser (MIXSEL) [810]. Optically pumped (OP) VECSELs and MIXSELs have, to our knowledge, generated shorter pulses and higher average powers than any other modelocked semiconductor laser (i.e. 135-fs pulses at 35-mW average power [11], $210 \mathrm{fs}$ pulses at $11 \mathrm{~mW}$ [12], $2.1 \mathrm{~W}$ in 4.7-ps pulses [13] and $6.4 \mathrm{~W}$ in 25-ps pulses from a MIXSEL [10]). In addition, SESAM-modelocked VECSELs have much better noise performance compared to modelocked EELs because of their short light interaction length and their high-Q cavity [14].

Further author information: barbarin@phys.ethz.ch - www.ulp.ethz.ch 
Electrical pumping (EP) of modelocked VECSELs is the clear next step towards high-power compact modelocked laser sources. In 2003, Novalux Corporation reported 900-mW output power in continuous wave (cw) from their proprietary EP-VECSEL, referred to the NECSEL $[15,16]$. OSRAM in 2007 presented a different approach, which is the monolithic integration of pump diodes through a VECSEL structure. From such integrated structure, $600 \mathrm{~mW}$ of output power in cW operation was obtained [17]. However the coupling between the pump laser cavities and the VECSEL gain is quite challenging and the pumped spot on the VECSEL gain is not necessarily uniform in the larger devices [18]. EPVECSELs have also been demonstrated at 1.55- $\mu \mathrm{m}[19,20]$ and 2.3- $\mu \mathrm{m}$ [21] wavelengths, but the difficulties encountered with the distributed Bragg reflectors (DBRs) at those wavelengths currently limit the cw power to the milliwatt level.

The first modelocked electrically pumped surface emitting laser was reported in 1993 with active modelocking producing 80-ps pulses using a liquid-nitrogen cooled vertical cavity surface emitting laser (VCSEL) structure [22]. Passively modelocked EP-VECSELs have, to our knowledge, only been reported using NECSEL chips. Modelocked operation has been demonstrated with $40 \mathrm{~mW}$ of average power in 57-ps pulses [23]. Shorter pulses of 15 ps have also been reported but at lower output power using a reversely biased SESAM very similar to the gain chip itself [24]. Modelocked EP-VECSELs requires a design which is not only optimized for high output power in cw but also for an optimal balance between electrical resistance, optical losses and dispersion. In 2008, we presented an EP-VECSEL design which is compatible with passive modelocking [25]. A first series of EP-VECSELs have been fabricated and the initial results are presented here.

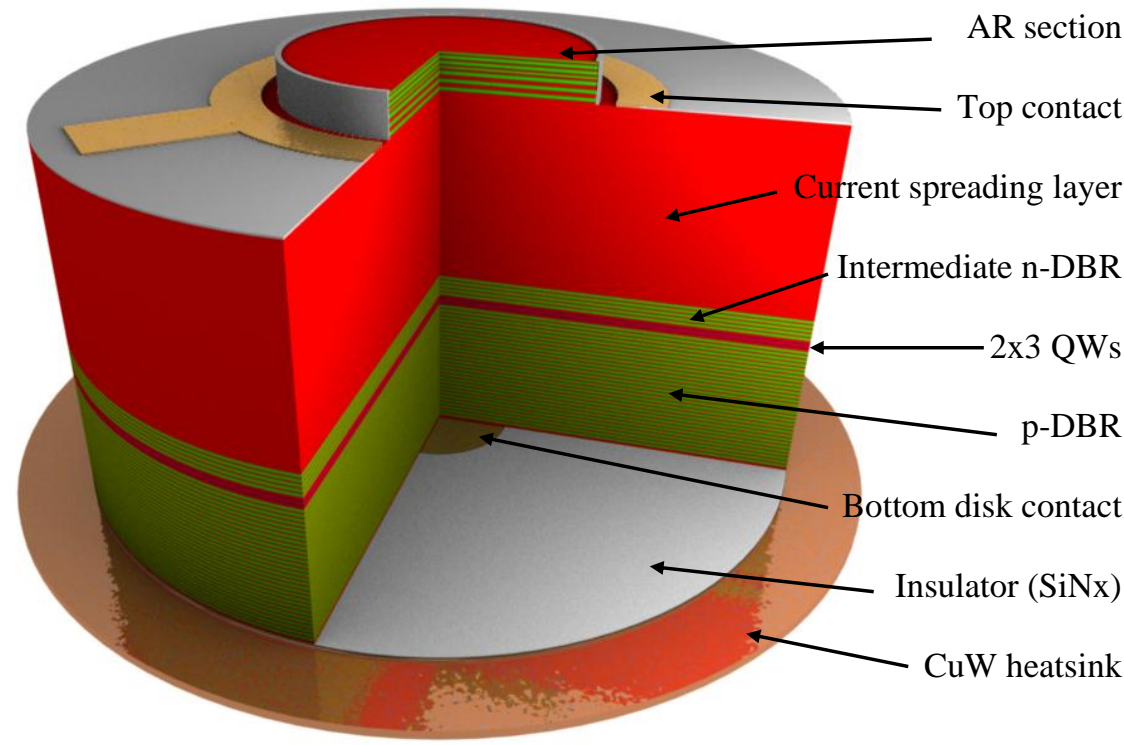

Figure 1. Schematic of our EP-VECSEL design (not to scale). The final structure as shown here is without the initial GaAs substrate and soldered on a CuW heatsink.

\section{EP-VECSEL DESIGN}

We previously discussed in [25] design guidelines of EP-VECSEL compatible with passive modelocking. Figure 1 shows a not-to-scale illustration of our EP-VECSEL chip, which is stretched vertically for better visibility. The confinement of the injected current into the center of the device is obtained by the use of a p-doped DBR with a small bottom disk contact (BDC) associated with on top a thick current spreading layer (CSL) with a ring electrode. The low mobility of the holes in the p-DBR confines the carriers to the volume above the BDC and the high mobility of the electrons in the thick CSL allows their recombination into the center of the device [25, 26]. The BDC determines the mode size of the EP-VECSEL as demonstrated in section 3, where the measured electroluminescence (EL) profiles are compared to the numerical model. 


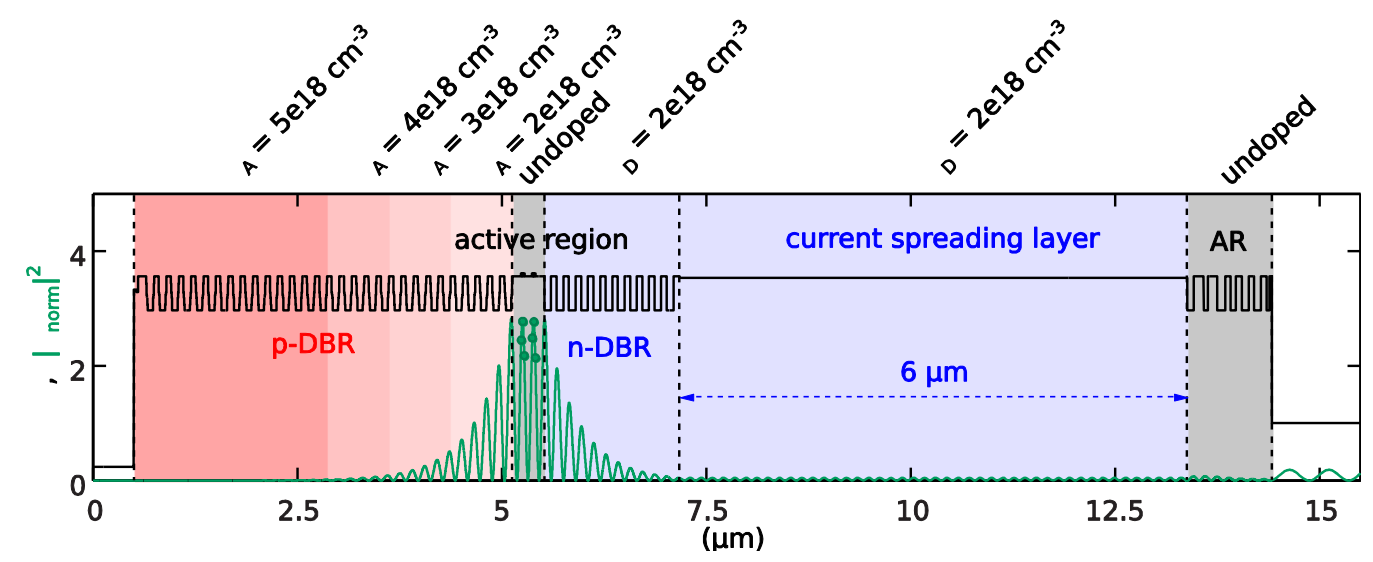

Figure 2: Refractive index (black line) and electrical field (green line) profiles along the EP-VECSEL structure. The doping levels are indicated on top of the diagram. The active region consists of 2 groups of 3 InGaAs QWs spaced by $10 \mathrm{~nm}$.

An optical simulation for the field enhancements inside the structure is shown in Figure 2. As discussed in [25] the nDBR enhances the field in the quantum wells (QWs) which compensates for the optical losses in the CSL, the n-doped DBR and the p-doped DBR. An antireflection (AR) section on top of the device prevents the CSL to act as a sub-cavity, which would deteriorate the device's performance.

The structure was grown by molecular beam epitaxy (MBE) in reverse order to allow for substrate removal. To reduce the resistance of the 30-pairs p-doped DBR, a $16 \mathrm{~nm}$ "staircase grading" with five $\mathrm{Al}_{(1-\mathrm{x})} \mathrm{Ga}_{\mathrm{x}} \mathrm{As}$ layers of different composition was inserted between each $\mathrm{AlAs} / \mathrm{GaAs}$ interface. Additionally, the doping levels were increased in layers where the electrical field is low. This adds no significant additional optical losses. The doping levels in the p-DBR (from bottom to top) are $[5,4,3,2] \cdot 10^{18} \mathrm{~cm}^{-3}$ for the pairs [1-15, 16-20, 21-25, 26-30], respectively. The active region consists of two groups of three InGaAs QWs spaced by $10 \mathrm{~nm}$ and placed in two antinodes of the electrical field. In this first realization, the intermediate $\mathrm{n}$-DBR has $11 \mathrm{AlAs} / \mathrm{GaAs}$ pairs without any grading, the doping concentration is $2 \cdot 10^{18} \mathrm{~cm}^{-3}$. The GaAs CSL is $6-\mu \mathrm{m}$ thick and n-doped with a concentration of $2 \cdot 10^{18} \mathrm{~cm}^{-3}$. The top AlAs/GaAs AR section remains undoped. The epitaxial layers have been fine tuned to obtain a lasing wavelength around $965 \mathrm{~nm}$ at an internal temperature of about $100-120^{\circ} \mathrm{C}$. Accordingly, the QWs emission wavelength has been detuned by $25 \mathrm{~nm}$. The different EP-VECSELs have been processed on a single chip as shown in Figure 3. For efficient heat removal, the chip is bonded to a $\mathrm{CuW}$ wafer, which has the same coefficient of thermal expansion as GaAs.
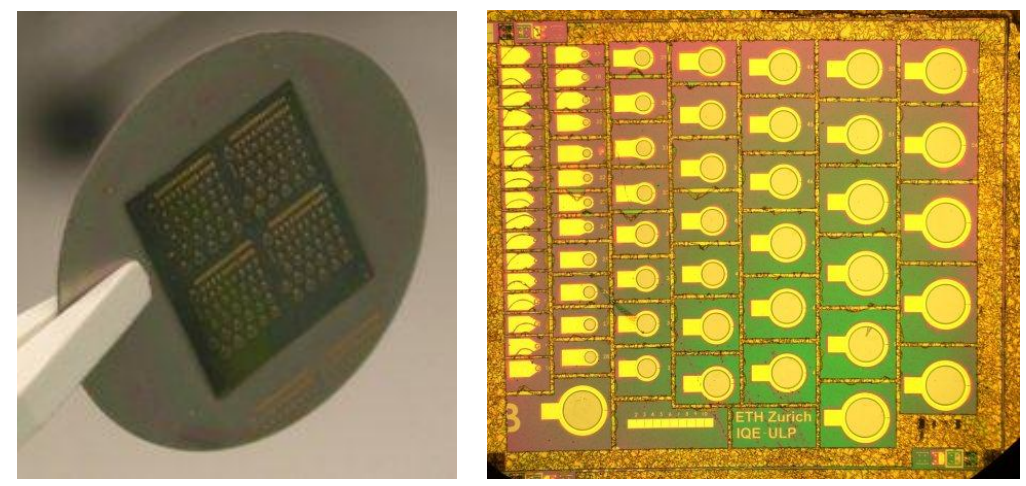

Figure 3: Pictures of a realized EP-VECSEL chip and a zoom on a section with 61 EP-VECSELs. The distortion in the picture is caused by the microscope.

The presented design should be suitable to be directly modelocked using an external SESAM as it is usually done with optically pumped ultrafast VECSELs [5]. To obtain stable modelocking, the saturation energy of the absorber needs to be lower than for the gain. This ratio can be controlled by the spot size on the SESAM and the design of the SESAM [26]. The intrinsic absorber properties can also be optimized, for instance, quantum-dot (QD) saturable absorbers have 
lower saturation fluence than QW saturable absorbers [27, 28]. For the generation of short pulses, the dispersion of the laser cavity needs to be optimized. We simulated and confirmed experimentally [29] that adding positive dispersion can compensate the nonlinear phase shift induced by strong semiconductor gain and absorber saturation.

\section{CURRENT CONFINMENT}

Power scaling of EP-VECSELs in a fundamental laser beam mode requires an efficient supply of carriers in the center of the active region even for large device diameters. The EL emission profile is taken as a measure for the current injection into the gain. The confinement of the carriers in the active region was also simulated using a coupled electro-optothermal model $[25,30]$. The simulation tool used incorporates microscopic carrier transport equations [30] and a thermionic emission model addresses abrupt hetero-interfaces [25]. The measured and simulated EL profiles of the EPVECSELs for different BDC diameters are compared in Figure 4. The measured EL profiles are in very good agreement with the simulation results. The profiles become flat-top-shaped and develop an intensity dip in the center of the device for diameters larger than $120 \mu \mathrm{m}$. Devices with BDC diameters up to $100 \mu \mathrm{m}$ are favorable for TEM $\mathrm{T}_{00}$ beams.

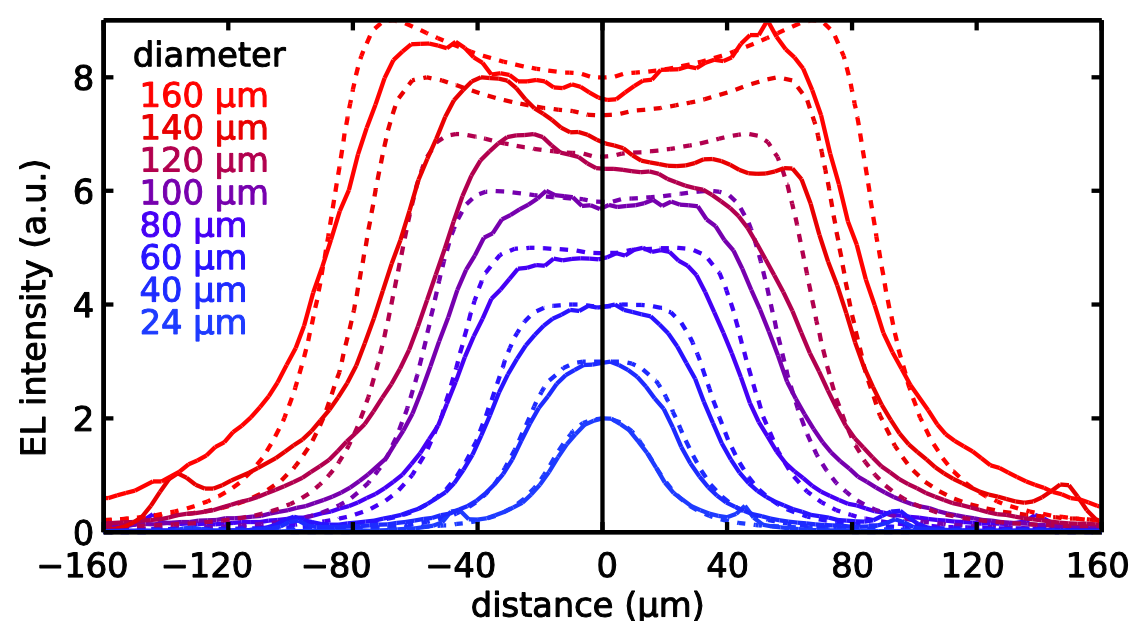

Figure 4: Measured (solid lines) and simulated (dashed lines) electroluminescence (EL) profiles of EP-VECSELs with different bottom disk contact diameters.

\section{LASING PERFORMANCE AND POWER SCALING}

We compared the lasing performance of EP-VECSELs with different aperture sizes at $3^{\circ} \mathrm{C}$ heatsink temperature in a simple straight cavity. The laser cavity was around $24.5 \mathrm{~mm}$ in length and terminated by a $25-\mathrm{mm}$ radius output coupler (OC). In Figure 5, the output power is plotted for 35 devices as a function of the BDC diameter in the case of a $10 \%$ transmission OC. Despite slight variations, there is a linear increase of the output power as a function of the BDC diameter. The power scalability of the current design is up to $120 \mathrm{~mW}$. We experienced that roll-over for small devices occurs at higher current densities than for larger devices. This gives some indication for thermal issues in the larger devices because the power does not increase proportionally to the active area. This could be improved by reducing the heat dissipation by a lower electrical resistance of the devices or by use of a bottom heatsink with higher thermal conductivity. The employed CuW heatsink has a thermal conductivity of $200 \mathrm{~W} \cdot \mathrm{K}^{-1} \cdot \mathrm{m}^{-1}$, which is two times lower than for copper and ten times lower than for diamond. The maximum output power in the current design is therefore limited by the strong internal heating as a result of an increased electrical and thermal resistance.

The light-current-voltage (LIV) curves of the EP-VECSEL delivering $120 \mathrm{~mW}$ of optical power using a $10 \%$ OC is shown in Figure 6. The EP-VECSEL gain structure has a 180- $\mu \mathrm{m}$ BDC diameter and 300- $\mu \mathrm{m}$ top contact electrode diameter. The thermal roll-over is obtained at $\approx 1 \mathrm{~A}$. The differential quantum efficiency at $750 \mathrm{~mA}$ is about $25 \%$ and the wall-plug efficiency about $5 \%$. 


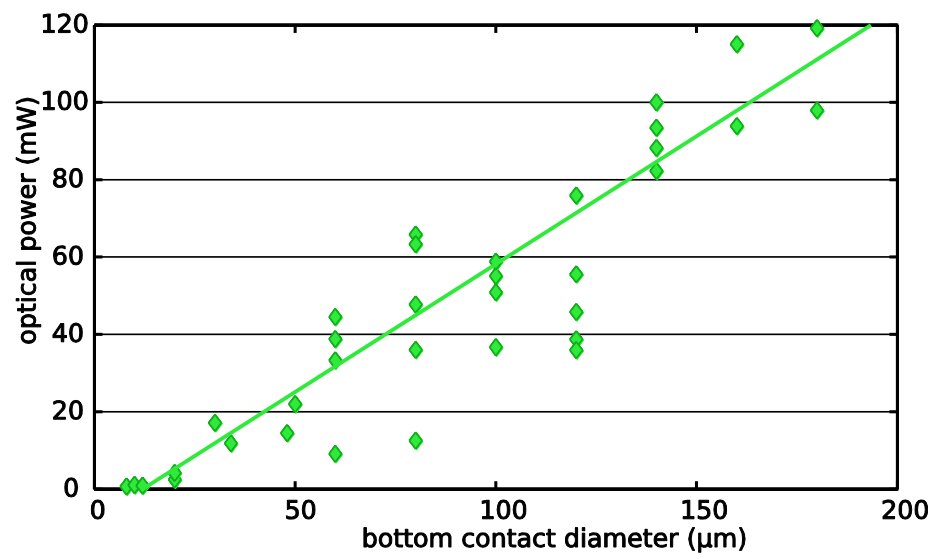

Figure 5: Output power of EP-VECSELs in a straight cavity with a $10 \%$ transmission output coupler as function of the bottom disk contact diameter. The heatsink temperature was kept at $3^{\circ} \mathrm{C}$.

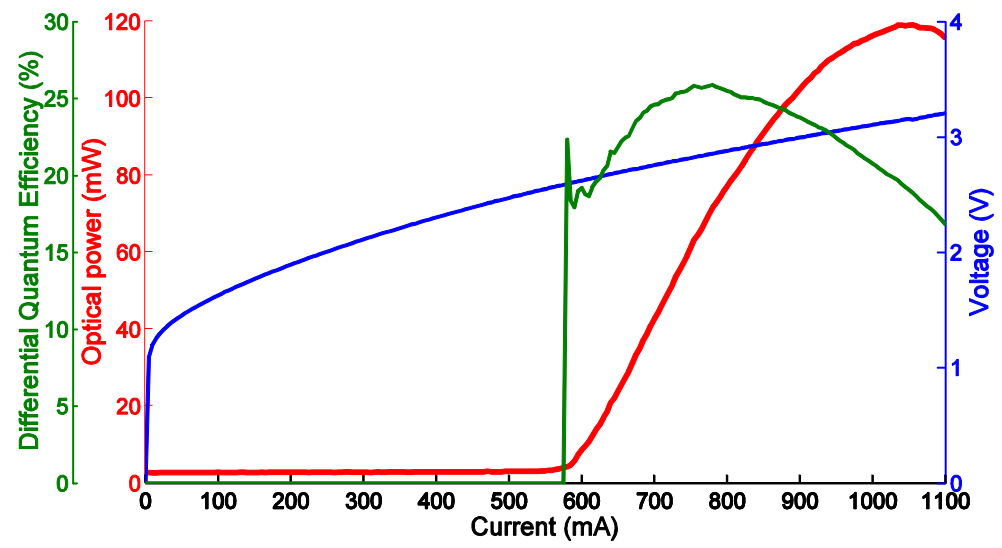

Figure 6: LIV curves from an EP-VECSEL with a disk contact diameter of $180 \mu \mathrm{m}$, top contact diameter of $300 \mu \mathrm{m}$, using a $10 \%$ output coupler. The heatsink temperature was kept at $3^{\circ} \mathrm{C}$.

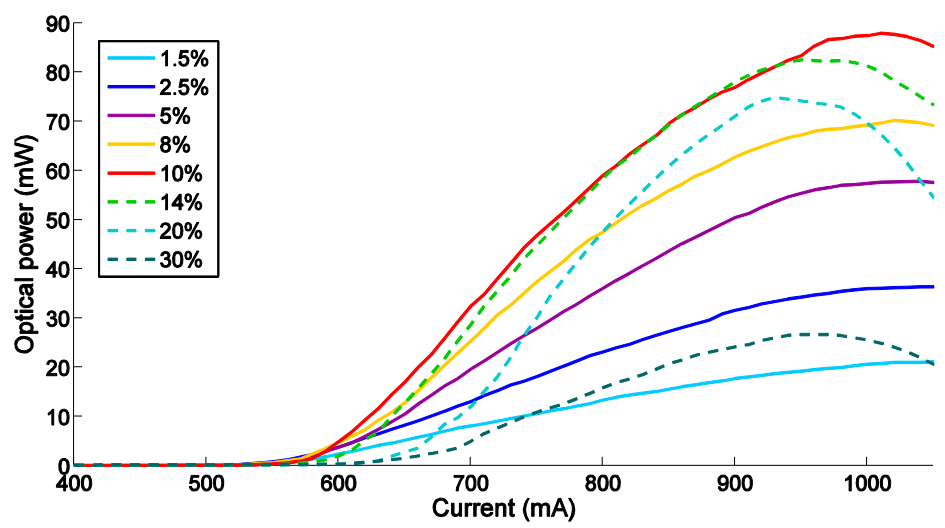

Figure 7: LI curves from an EP-VECSEL with a disk contact diameter of $180 \mu \mathrm{m}$ using different output coupler transmission. The heatsink temperature was kept at $20^{\circ} \mathrm{C}$.

In Figure 7, the light-current curves of an EP-VECSEL with a BDC diameter of $180 \mu \mathrm{m}$ are shown for different OC transmissions. The optimum transmission for high power would be $\approx 14 \%$ at $20^{\circ} \mathrm{C}$ heat sink temperature. This value is much higher than what is typically used in OP-VECSELs because the EP-VECSEL intermediate n-DBR already reflects $\sim 90 \%$ of the light in this initial realization. 


\section{CONCLUSION}

We presented a first series of EP-VECSELs of different sizes based on our design guidelines published in [25]. We described the design used for the fabrication, a comparison of the EL profile to our coupled electro-opto-thermal model and the lasing performance. The challenge for high-power modelocked EP-VECSELs is first to get high power levels by scaling the devices laterally keeping a homogeneous electrical pumping and second to balance the competing requirements of low electrical resistance, low optical losses and controlled dispersion while maintaining fundamental mode operation for stable modelocking. For the EP-VECSELs presented here, the entire active area can be pumped efficiently with sufficient homogeneity even for large diameter devices. This is in very good agreement with the simulation results. Devices with BDC diameters of up to $100 \mu \mathrm{m}$ are favorable for $\mathrm{TEM}_{00}$ output beams. Promising output power levels were obtained in $\mathrm{cw}$ and could scale the power up to $120 \mathrm{~mW}$ despite a higher resistance than designed. We expect that the next generation of EP-VECSELs with improved designs will result in higher output powers to support modelocking with an external low saturation fluence QD-SESAM.

\section{REFERENCES}

[1] E. Murphy, "The semiconductor laser: Enabling optical communication," Nat. Photon. 4, $287-287$ (2010).

[2] J. J. Plant, J. T. Gopinath, B. Chann, D. J. Ripin, R. K. Huang, and P. W. Juodawlkis, "250 mW, $1.5 \mu \mathrm{m}$ monolithic passively modelocked slab-coupled optical waveguide laser," Opt. Lett. 31, 223-225 (2006).

[3] T. Schlauch, M. Li, M. R. Hofmann, A. Klehr, G. Erbert, and G. Trankle, "High peak power femtosecond pulses from modelocked semiconductor laser in external cavity," Electronics Letters 44, 678-679 (2008).

[4] M. Kuznetsov, F. Hakimi, R. Sprague, and A. Mooradian, "High-Power (>0.5-W CW) Diode-Pumped VerticalExternal-Cavity Surface-Emitting Semiconductor Lasers with Circular TEM00 Beams," IEEE Photon. Technol. Lett. 9, 1063-1065 (1997).

[5] U. Keller and A. C. Tropper, "Passively modelocked surface-emitting semiconductor lasers," Phys. Rep. 429, 67120 (2006)

[6] U. Keller, "Recent developments in compact ultrafast lasers" Nature 424,831-838 (2003).

[7] U. Keller, K. J. Weingarten, F. X. Kärtner, D. Kopf, B. Braun, I. D. Jung, R. Fluck, C. Hönninger, N. Matuschek, and J. Aus der Au, "Semiconductor saturable absorber mirrors (SESAMs) for femtosecond to nanosecond pulse generation in solid-state lasers," IEEE J. Sel. Top. Quantum Electron. 2, 435-453 (1996).

[8] D. J. H. C. Maas, A.-R. Bellancourt, B. Rudin, M. Golling, H. J. Unold, T. Südmeyer, and U. Keller, "Vertical integration of ultrafast semiconductor lasers," Appl. Phys. B 88, 493-497 (2007).

[9] A.-R. Bellancourt, D. J. H. C. Maas, B. Rudin, M. Golling, T. Südmeyer, and U. Keller, "Modelocked Integrated External-Cavity Surface Emitting Laser (MIXSEL)," IET Optoelectronics 3, 61-72 (2009).

[10] B. Rudin, V. J. Wittwer, D. J. H. C. Maas, M. Hoffmann, O. D. Sieber, Y. Barbarin, M. Golling, T. Südmeyer, and U. Keller, "High-power MIXSEL: an integrated ultrafast semiconductor laser with $6.4 \mathrm{~W}$ average power," Accepted for publication in Optics Express, (2010).

[11] A. H. Quarterman, K. G. Wilcox, V. Apostolopoulos, Z. Mihoubi, S. P. Elsmere, I. Farrer, D. A. Ritchie, and A. Tropper, "A passively mode-locked external-cavity semiconductor laser emitting 60-fs pulses," Nat. Photonics 3 , 729-731 (2009).

[12] P. Klopp, U. Griebner, M. Zorn, A. Klehr, A. Liero, M. Weyers, and G. Ebert, "Mode-Locked InGaAs-AlGaAs disk laser generating sub-200-fs pulses, pulse picking and amplification by a tapered diode amplifier," Opt. Express 17, 10820-10834 (2009).

[13] A. Aschwanden, D. Lorenser, H. J. Unold, R. Paschotta, E. Gini, and U. Keller, "2.1-W picosecond passively mode-locked external-cavity semiconductor laser," Opt. Lett. 30, 272-274 (2005).

[14] A. H. Quarterman, K. G. Wilcox, S. P. Elsmere, Z. Mihoubi, and A. C. Tropper, "Active stabilisation and timing jitter characterisation of sub-500 fs pulse passively modelocked VECSEL," Electron. Lett. 44, 1135-1137 (2008).

[15] J. G. McInerney, A. Mooradian, A. Lewis, A. V. Shchegrov, E. M. Strzelecka, D. Lee, J. P. Watson, M. Liebman, G. P. Carey, B. D. Cantos, W. R. Hitchens, and D. Heald, "High-power surface emitting semiconductor laser with extended vertical compound cavity," Electron. Lett. 39, 523-525 (2003).

[16] J. G. McInerney, A. Mooradian, A. Lewis, A. V. Shchegrov, E. M. Strzelecka, D. Lee, J. P. Watson, M. K. Liebman, G. P. Carey, A. Umbrasas, C. A. Amsden, B. D. Cantos, W. R. Hitchens, D. L. Heald, V. V. Doan, and J. 
L. Cannon, "Novel 980-nm and 490-nm light sources using vertical cavity lasers with extended coupled cavities," Proc. SPIE 4994, 21-31 (2003).

[17] S. Illek, T. Albrecht, P. Brick, S. Lutgen, I. Pietzonka, M. Furitsch, W. Dieh, J. Luft, and K. Streubel, "VerticalExternal-Cavity Surface-Emitting Laser With Monolithically Integrated Pump Lasers," IEEE Photon. Technol. Lett. 19, 1952-1954 (2007).

[18] W. Diehl, T. Albrecht, P. Brick, M. Furitsch, S. Illek, S. Lutgen, I. Pietzonka, J. Luft, and W. Stolz, "High power semiconductor disk laser with monolithically integrated pump lasers," Proc. SPIE 6997, 699711-7 (2008).

[19] M. E. Kurdi, S. Bouchoule, A. Bousseksou, I. Sagnes, A. Plais, M. Strassner, C. Symonds, A. Garnache, and J. Jacquet, "Room-temperature continuous-wave laser operation of electrically-pumped $1.55 \mu \mathrm{m}$ VECSEL," Electron. Lett. 40, 671-672 (2004).

[20] A. Bousseksou, S. Bouchoule, M. Kurdi, M. Strassner, I. Sagnes, P. Crozat, and J. Jacquet, "Fabrication and characterization of 1.55 um single transverse mode large diameter electrically pumped VECSEL," Optical and Quantum Electronics 38, 1269-1278 (2006).

[21] A. Harkonen, A. Bachmann, S. Arafin, K. Haring, J. Viheriala, M. Guina, and M.-C. Amann, "2.34 um electrically pumped VECSEL with buried tunnel junction," Proc. SPIE 7720,772015-7 (2010).

[22] W. Jiang, M. Shimizu, R. P. Mirin, T. E. Reynolds, and J. E. Bowers, "Electrically pumped mode-locked verticalcavity semiconductor lasers," Opt. Lett. 18, 1937-1939 (1993).

[23] K. Jasim, Q. Zhang, A. V. Nurmikko, A. Mooradian, G. Carey, W. Ha, and E. Ippen, "Passively modelocked vertical extended cavity surface emitting diode laser," Electron. Lett. 39, 373-375 (2003).

[24] K. Jasim, Q. Zhang, A. V. Nurmikko, E. Ippen, A. Mooradian, G. Carey, and W. Ha, "Picosecond pulse generation from passively modelocked vertical cavity diode laser at up to $15 \mathrm{GHz}$ pulse repetition rate," Electron. Lett. 40, 3435 (2004).

[25] P. Kreuter, B. Witzigmann, D. J. H. C. Maas, Y. Barbarin, T. Südmeyer, and U. Keller, "On the Design of Electrically-Pumped Vertical-External-Cavity Surface-Emitting Lasers," Appl. Phys. B 91, 257-264 (2008).

[26] G. J. Spühler, K. J. Weingarten, R. Grange, L. Krainer, M. Haiml, V. Liverini, M. Golling, S. Schon, and U. Keller, "Semiconductor saturable absorber mirror structures with low saturation fluence," Appl. Phys. B 81, 27-32 (2005).

[27] D. J. H. C. Maas, A. R. Bellancourt, M. Hoffmann, B. Rudin, Y. Barbarin, M. Golling, T. Südmeyer, and U. Keller, "Growth parameter optimization for fast quantum dot SESAMs," Opt. Express 16, 18646-18656 (2008).

[28] A.-R. Bellancourt, Y. Barbarin, D. J. H. C. Maas, M. Shafiei, M. Hoffmann, M. Golling, T. Südmeyer, and U. Keller, "Low Saturation Fluence Antiresonant Quantum Dot SESAMs for MIXSEL integration," Opt. Express 17, 9704-9711 (2009).

[29] M. Hoffmann, O. D. Sieber, D. J. H. C. Maas, V. J. Wittwer, M. Golling, T. Südmeyer, and U. Keller, "Experimental verification of soliton-like pulse-shaping mechanisms in passively mode-locked VECSELs," Opt. Express 18, 10143-10153 (2010).

[30] B. Witzigmann, A. Bäcker, and S. Odermatt, "Physics and Simulation of Vertical-Cavity Surface-Emitting Lasers," Journal of Computational and Theoretical Nanoscience 5, 1058-1071 (2008). 